\title{
US and Cuban Scientists Forge Collaboration on Arbovirus Research
}

\author{
Jorge Pérez-Ávila MD MS, Maria G. Guzmán-Tirado MD PhD DrSc, Jorge Fraga-Nodarse PhD, F. Gray Handley MSPH, \\ James Meegan MD, Jose L. Pelegrino-Martínez de la Cotera MS, Anthony S. Fauci MD
}

\begin{abstract}
After December 17, 2014, when the US and Cuban governments announced their intent to restore relations, the two countries participated in various exchange activities in an effort to encourage cooperation in public health, health research and biomedical sciences. The conference entitled Exploring Opportunities for Arbovirus Research Collaboration, hosted at Havana's Hotel Nacional, was part of these efforts and was the first major US-Cuban scientific conference in over 50 years. Its purpose was to share information about current arbovirus research and recent findings, and to explore opportunities for future joint research. The nearly 100 participants included leading arbovirus and vector transmission experts from ten US academic institutions, NIH, CDC, FDA and the US Department of Defense. Cuban participants included researchers, clinicians and students from Cuba's Ministry of Public Health, Pedro Kourí Tropical Medicine Institute, Center for Genetic Engineering and Biotechnology,
\end{abstract}

\section{INTRODUCTION}

On December 17, 2014, when the US and Cuban governments announced their intent to restore relations, US President Barack Obama emphasized the implications of rapprochement for health cooperation.[1] Prior to this announcement, a group of US scientists and policy experts, sponsored by the American Association for the Advancement of Science (AAAS), traveled to Havana in April 2014 to meet Cuban scientists, physicians and policy makers; visit research and public health facilities; discuss opportunities for further interaction; and sign a memorandum of understanding between the Cuban Academy of Sciences and the AAAS to launch further exploration of mutual health research interests.[2]

In August 2015, the Cuba's Pedro Kourí Tropical Medicine Institute (IPK) sponsored the 14th edition of its research and training conference, the International Dengue Course, which it has organized in Havana since 1987. Participants included dengue viral disease scientists from the US National Institutes of Health (NIH) and CDC. In October 2015, Cuban scientific leaders attended, for the first time, the annual meeting of the American Society of Tropical Medicine and Hygiene (ASTMH) in New Orleans, where they participated in a US-Cuban informationsharing symposium organized by the NIH's Fogarty International Center, the ASTMH and PAHO.[3-4] This symposium, CubaU.S: Building Bridges Through Science and Global Health, was

IMPORTANCE Cuba's experience in arbovirus research and health strategies for mosquito control complement US CDC's strengths in research and epidemiologic surveillance. Rapidly emerging threats from arboviral illness, extension of vector habitats, and proximity make US-Cuba collaboration not only mutually beneficial, but imperative.
Center for State Control of Medicines and Medical Devices and other health research and regulatory organizations. Topics highlighted at the three-day meeting included surveillance, research and epidemiology; pathogenesis, immunology and virology; treatment and diagnosis; vector biology and control; vaccine development and clinical trials; and regulatory matters. Concurrent breakout discussions focused on novel vector control, nonvector transmission, community engagement, Zika in pregnancy, and workforce development. Following the conference, the Pedro Kouri Tropical Medicine Institute and the US National Institute of Allergic and Infectious Diseases have continued to explore ways to encourage and support scientists in Cuba and the USA who wish to pursue arbovirus research cooperation to advance scientific discovery to improve disease prevention and control.

KEYWORDS Arboviruses, flavivirus, Zika virus, chikungunya virus, dengue virus, research, disease vectors, Cuba, USA followed by an unprecedented visit by the participating Cuban scientists to the NIH in Bethesda, Maryland. During the visit, $\mathrm{NIH}$ leadership explored opportunities for chronic and infectious disease research collaborations with Cuba.[5]

Following further official contacts and reestablished diplomatic relations, Cuba's Vice-Minister of Public Health, Dr José Ángel Portal Miranda, visited the USA early in 2016. He included NIH and other agencies of the US Department of Health and Human Services (HHS) on his itinerary. In June, following the historic visit of President Obama to Cuba in March 2016, where health research was again highlighted as a key area for expanded cooperation, Cuba's Minister of Public Health, Dr Roberto Morales Ojeda, visited Washington DC to meet with HHS Secretary Sylvia Burwell. During this visit, the two leaders signed a memorandum of understanding to establish cooperation in public health, health research and biomedical sciences, specifically calling for collaboration to confront Zika, dengue, chikungunya and other arboviruses.[6] Also during this visit, leadership from Cuba's Ministry of Public Health (MINSAP), IPK, and the NIH's National Institute of Allergy and Infectious Diseases (NIAID), agreed on the value of convening a scientific meeting to explore arbovirus research collaboration opportunities, given the emerging potential threat of Zika, dengue and chikungunya in the southern USA and the Caribbean region. A bilateral scientific planning committee was established with representation from NIH, CDC and the US FDA to assist the IPK in conference planning.

Also significantly, on October 17, 2016, the US Department of the Treasury's Office of Foreign Assets Control (OFAC) issued a regulatory amendment that authorized (under general license) expanded US-Cuban engagement in commercial and noncommercial joint medical research and training.[7] Furthermore, during the same week (October 19) a preliminary US-Cuban arbovirus research meeting was held in Havana, in conjunction with a $\mathrm{PAHO}-$ organized regional arbovirus control 
meeting (October 20-21).[8] HHS Secretary Burwell attended the $\mathrm{PAHO}$ regional meeting and used the opportunity to visit Cuban health facilities and research institutions. She also signed another memorandum of understanding with MINSAP to foster cancer research cooperation.[9]

\section{COLLABORATION}

After two years of preparations, IPK, MINSAP and other Cuban health agencies and research centers, together with government and academic scientists from the USA, convened the first major US-Cuban scientific conference in over 50 years. The conference, Exploring Opportunities for Arbovirus Research Collaboration, was held at the Hotel Nacional in Havana (November 28-30, 2016). Its purpose was to share recent findings from arbovirus research and explore future joint research opportunities.

The nearly 100 participants included leading arbovirus and transmission vector experts from ten US academic institutions, $\mathrm{NIH}, \mathrm{CDC}, \mathrm{FDA}$ and the US Department of Defense. Cuban participants included researchers, clinicians and students from MINSAP, IPK, Center for Genetic Engineering and Biotechnology, Center for State Control of Medicines and Medical Devices, and other health research and regulatory centers. Topics highlighted at the meeting included surveillance research and epidemiology; pathogenesis, immunology, and virology; treatment and diagnosis; vector biology and control; vaccine development and clinical trials; and regulatory matters. Concurrent breakout discussions focused on novel vector control, nonvector transmission, community engagement, Zika in pregnancy, and workforce development.

Presentations on arbovirus epidemiology noted that it took a decade for dengue to spread and reach 1.5 million cases in the Americas Region. However, with ever-increasing travel, urbanization and mosquito vector expansion, the more recent chikungunya and Zika epidemics reached these prevalence levels in a much shorter period.

Other presentations described Cuba's robust, well-organized infectious disease surveillance system. The system is based on a network of clinics and hospitals, relying on a provider base of 8 physicians and 8 nurses per 1000 population. Cuba's long-standing program to limit vector-borne diseases stresses community involvement in vector control and includes yearround nationwide coverage aimed at eliminating mosquito breeding foci.

\section{...it took a decade for dengue to spread and reach 1.5 million cases in the Americas Region. However, chikungunya and Zika epidemics reached these prevalence levels in a much shorter period.}

An active surveillance system includes a network of laboratories and a national reference center (IPK) that has a decades-long history of arboviral disease diagnosis.

Many of these laboratories utilize state-of-the-art nucleic acid detection and serological assays to diagnose the island's most imminent threats-dengue, chikungunya and Zika viruses. Diagnosticians exchanged topical information on new assays, with a focus on evolving techniques that improve specificity where cross reactivity between flaviviruses_including dengue, West Nile, yellow fever and Zika-remains a problem.
The scope of Cuban arbovirus research was presented in detail, particularly IPK's basic, translational and applied research programs, which include those focused on viral epidemiology, host factors influencing viral pathogenesis, virus evolution and molecular biology, vaccine and antiviral development, and environmental studies on mosquito control.

Because of their central role in arbovirus transmission to humans and their expansion into new geographic areas in the region, Aedes aegypti and $A$. albopictus were extensively discussed. The history of Cuba's successful programs to control $A$. aegypti in the 1980s was presented, with a sobering coda on its current resurgence throughout the country.

Vaccines were another active focus of the conference with an emphasis on development and clinical evaluation of new dengue and chikungunya vaccines, and ongoing early efforts to develop Zika vaccines. The NIH investigators reviewed encouraging early clinical studies of a chikungunya virus-like particle vaccine and of a live-attenuated, recombinant tetravalent dengue vaccine. Cuban scientists described promising preclinical testing of a subunit dengue vaccine developed to protect against all four serotypes.

Antiviral therapeutics were discussed, including their potential role as short-term preventive interventions during arbovirus outbreaks where registered vaccines are unavailable. Discussions of retesting and repurposing established therapeutic drugs led to conclusions that this approach to emerging arbovirus outbreaks deserves further evaluation. Researchers reviewed the current use of arbovirus animal models and emphasized the need for wellcharacterized models for the clinical syndromes of microcephaly and Guillain-Barré that appear to be linked to Zika infection. Throughout the meeting, participants identified numerous fields for potential collaboration, and many expressed a desire to pinpoint specific areas of joint research where collaboration might be initiated to address critical questions related to basic understanding of arboviruses and their vectors. US scientists recognized Cuba's strong track record in arbovirus research and control, making the prospect of collaboration attractive, with substantial opportunities for synergy.

\section{ANALYSIS}

Shared concern about mosquito-borne diseases is spurring cooperation among Cuban and US scientists. The conference helped build on the two countries' strengths in research capacity and experience, to initiate new collaborative research studies, which should have important implications for more effectively preventing and addressing arboviral infections in both countries, the Americas Region and the world. Following the conference, IPK and NIAID have continued to explore ways to encourage and support scientists in Cuba and the USA who wish to pursue arbovirus research cooperation to advance scientific discovery to benefit population health.

One of the most important results was CRDF Global's US-Cuba Collaborative Arbovirus Research Initiative, 2017 (jointly funded with NIAID), which considered proposals from US and Cuban scientists working jointly in arbovirus research. IPK and US institutions submitted seven joint research grant proposals, four of which were approved and are due to start in 2018. One of these, involving IPK and the University of California at San Diego, will focus on the role of OSBPL10, RXRA and other lipids participating 
in the RXRA metabolic pathway in maturation, replication, assembly and secretion of dengue virus. Another two projects will address entomological studies; one, with Johns Hopkins University, will aim to determine factors influencing $A$. aegypti competence as a vector for dengue and Zika viruses in Cuba; the other, with the University of Kentucky, will be devoted to the use of Wolbachia in control of residual populations of $A$. aegypti and $A$. albopictus in Cuba. A final project, with the University of North Carolina at Chapel Hill, will evaluate changes in antibody expression in Cuban individuals after primary dengue infection.

As noted by many leaders since reestablishment of diplomatic relations, health and scientific cooperation can provide a foundation for US-Cuba relationship building. The severity of arboviral diseases' potential outcomes (including for infants and pregnant women, not all of which sequelae are well understood), the increased rapidity with which recent outbreaks have evolved, the anticipated climate-change driven extensions of vector habitats,[10] and the fact that only 90 miles separate Cuba from the USA, make the rapidly emerging threats of Zika, dengue, chikungunya, and other arboviral diseases in the Gulf and Caribbean region fertile ground for collaborative arbovirus research that would broadly benefit public health in both countries. Furthermore, jointly planned, managed and executed infectious disease research can provide a model for other US-Cuba scientific cooperation. As the top infectious disease research institutes in their respective countries, IPK and NIAID remain committed to helping lead the way. Because IPK is a PAHO/WHO collaborating center for dengue and other arboviruses, (and in fact is the dengue lead in the Arbovirus Diagnosis Laboratory Network of the Americas), its experience in research and participation in health strategies for mosquito control are vital to the USA and other countries, complementing CDC's strengths in research and epidemiological surveillance.

\section{ACKNOWLEDGMENTS}

The authors thank MINSAP, PAHO and IPK for sponsorship and support of the November 2016 conference; as well as the organizing committee, speakers and participants who contributed to its successful outcomes. - - M

\section{REFERENCES}

1. The White House [Internet]. Washington, D.C.: The White House; c2018. Office of the Press Secretary. Speeches and Remarks. Statement by the President on Cuba policy changes; 2014 Dec 17 [cited 2017 Jan 18]. Available from: https://www.whitehouse.gov/ the-press-office/2014/12/17/statement-president -cuba-policy-changes

2. Wern K. Science diplomacy visit to Cuba produces historic agreement. American Association for the Advancement of Science [Internet]. 2014 Apr 30 [cited 2016 Dec 8]; [about 4 screens]. Available from: https://www.aaas.org/ news/science-diplomacy-visit-cuba-produces -historic-agreement

3. American Society of Tropical Medicine and Hygiene [Internet]. Illinois: American Society of Tropical Medicine \& Hygiene; c2018. CubaU.S: Building Bridges Through Science and Global Health. Session detail; 2015 [cited 2016 Dec 8]; [about 2 screens]. Available from: http:// www.abstractsonline.com/Plan/ViewSession .aspx?sKey=0125d35d-66eb-4470-9a76-b57 $48 c 1 c 7 b 2 e \& m K e y=a b 652 f d f-0111-45 c 7-a 5 e 5$ -0ba9d4af5e12

4. Puderbaugh A. US scientists explore research partnerships with Cuba [Internet]. Bethesda: Fogarty International Center; 2015 Dec [cited 2017 Jan 18]; [about 2 screens]. Available from: https://www.fic.nih.gov/News/ GlobalHealthMatters/november-december-2015/ Pages/us-cuba-joint-scientific-priorities.aspx

5. Bausch DG, Kourí V, Resik S, Acosta B, Guillen G, Goraleski K, et al. The Cuba-United States Thaw: Building Bridges through Science and Global Health. Am J Trop Med Hyg [Internet]. 2017 Jun [cited 2017 Oct 8];96(6):1267-9. Available from: https://www.ncbi.nlm.nih.gov/ pmc/articles/pmid/28719268/
6. The White House [Internet]. Washington, D.C. The White House; c2018. Office of the Press Secretary. Presidential policy directive - United States-Cuba normalization; 2016 Oct 14 [cited 2016 Dec 13]. Available from: https://www .whitehouse.gov/the-press-office/2016/10/14/ presidential-policy-directive-united-states-cuba -normalization

7. U.S. Department of Treasury [Internet]. Washington, D.C.: U.S. Department of Treasury; c2018. U.S. Department of Treasury Resource Center. Publication of updated Cuban Assets Control Regulations (CACR); 2016 Oct 14 [cited 2016 Dec 13]. Available from: https://www .treasury.gov/resource-center/sanctions/OFAC -Enforcement/Pages/20161014.aspx

8. Pan American Health Organization [Internet]. Washington, D.C.: Pan American Health Organization; c2018. Media Center. Health leaders discuss action against mosquitoborne viruses such as Zika and dengue; 2016 Oct 21 [cited 2017 Jan 19]; [about 3 screens]. Available from: http://www.paho .org/hq/index.php?option=com_content\&view $=$ article \&id $=12641 \% 3$ Ahealth-leaders-discuss -action-against-mosquito-borne-viruses-zika -dengue\&ltemid=1926\&lang=en

9. Burwell SM. The promise of a strong U.S.-Cuba health partnership [Internet]. U.S. Department of State Official Blog; 2016 Nov 7 [cited 2016 Dec 13]. Available from: http://2007-2017-blogs.state .gov/stories/2016/11/07/promise-strong-us-cuba -health-partnership.html

10. Johnson TL, Haque $U$, Monaghan AJ, Eisen L, Hahn MB, Hayden MH, et al. Modeling the Environmental Suitability for Aedes (Stegomyia) aegypti and Aedes (Stegomyia) albopictus (Diptera: Culicidae) in the Contiguous United States. J Med Entomol. 2017 Nov 7;54(6):1605-14.

\section{THE AUTHORS}

Jorge Pérez-Ávila (Corresponding author: jorge.perez@ipk.sld.cu), physician specializing in clinical pharmacology. Full professor and adviser to the Director, Pedro Kourí Tropical Medicine Institute (IPK), Havana, Cuba.

María G. Guzmán-Tirado, virologist. Distinguished researcher and full professor, IPK; PAHO/WHO Collaborating Center for the Study and Control of Dengue, IPK, Havana, Cuba.

Jorge Fraga-Nodarse, biochemist. Senior researcher, Parasitology Department, IPK, Havana, Cuba.

F. Gray Handley, Associate Director for International Research Affairs, National Institute of Allergy and Infectious Diseases (NIAID), National Institutes of Health (NIH), Bethesda (MD), USA.

James Meegan, virologist. Director of the Office of Global Research, NIAID, NIH, Bethesda (MD), USA.

José L. Pelegrino-Martínez de la Cotera, virologist. IPK, Havana, Cuba.

Anthony S. Fauci, immunologist. Director, NIAID, NIH, Bethesda (MD), USA.

Submitted: July 2, 2017

Approved: March 6, 2018

Disclosures: None 